When sufficient purified and identified material of any of the viruses is available, it passes to the Microbiological Research Establishment (MRE) at Porton, working under contract from the MOD. One of the problems that is arising at this third stage is that although the MRE has the necessary facilities for undertaking any tests that may be required to check the toxicity of the viruses for vertebrates, their staff have no experience in handling, or working with, insects - and any results from Porton will need to be checked against the insect host. Arrangements are therefore being made, with the cooperation also of the Medical Research Council, for the closest possible collaboration between MRE and UIV at this stage. Only when a virus has been cleared of any potential ecological hazard at the laboratory level can the fourth stage of field testing, in the areas where its use is envisaged, be started. The first candidate to reach this stage is likely to be the virus affecting Spodoptera exempta, if only because of the MOD's very special interest in protecting the grasslands of the Commonwealth countries (and others) of East Africa. Meanwhile, however, research into the ecology of an active, natural outbreak of an insect virus is also being carried out by staff from the UIV. The insect concerned is, again, the spruce sawfly, Gilpinia hercyniae an outbreak of which was identified some years ago in the Forestry Commission's Hafren Forest in Mongomeryshire, UK. Dr Tinsley was already applying for permission to experiment with the relevant virus at Hafren, when, in 1970, a natural infection was discovered in the forest, which thus became an ideal field laboratory for research into the ecology and epidemiology of a natural insect virus outbreak.

Although in the UK this fundamental approach to the development of viral pesticides has been adopted and is being rigorously pursued, the same is not true elsewhere. Viral pesticides have for some time now been on the market in the USA and they are known to have been used extensively for some years in the USSR, particularly against pests of forest trees and certain industrial crops. What is happening in Russia is not at all clear, nor is it known what precautions are taken or what problems, if any, have arisen. But certain of the difficulties that the pesticide industry may face, when it comes to commercial production of a virus that has successfully passed through all four preliminary stages, have recently become evident from American experience. The viruses concerned are again those affecting certain lepidopterous larvae, namely the genus Heliothis, including
H. zea (on cotton, and probably the UIV's next target insect), $H$. virescens and $H$. armigera, pests of tobacco and maize respectively; the area on which Heliothis NPV has been used is said to be as much as five million acres. Successes in field trials on a vast scale led, in 1971 , to a "temporary exemption from tolerance requirements" on the part of the ES Environment Protection Agency, and when this was later confirmed, the way was clear to go ahead with commercial production. Two companies, International Mineral Corporation and Nutrilite, put viral pesticides on the market-Viron and VHZ respectively-confident that they had at last achieved a breakthrough. Prolonged testing and field use had indicated that the degree of control was at least as good as that with chemical insecticides, whereas after 12 years of experimentation there was said to be no change in the specificity of the virus and no sign of any resistance on the part of the host. And yet, within recent months, the product actually put on sale has seemed to be less effective than those years of testing had led the manufacturers to believe. The extent to which this is so, why it should be, and how it can have happened, is not clear.

While these and other developments are going ahead in the UK and the USA, no one, in the UK at least, believes that rapid and sensationally successful control of the target pests is just around the corner. Problems will certainly arise at higher altitudes for example, unless some way can be found of getting over the undeniable fact that NPVs are inactivated by ultraviolet light (although one recent report indicated the reverse effect for the virus of one Lepidopteran, Autographa californica at least when grown in vitro). Then there seem to be problems relating to the effect on the virus of various leaf surfaces. A great deal of work will have to be done on the evolution of suitable formulations for large scale manufacture and application of the commercial productespecially in view of recent American experience. Finally, there is some uneasiness about the adequacy of the protocols for safety testing, so far developed by the WHO on the basis of those used at present in the United States-and themselves developed for non-replicating, easily identifiable chemical pesticides.

But once these new pesticidal agents become available, unequivocally identified and rigorously tested, in standardised formulations that can be used in complete safety, a new and most powerful weapon will be available against many of the pests that threaten the world's essential food supplies and industrial crops.

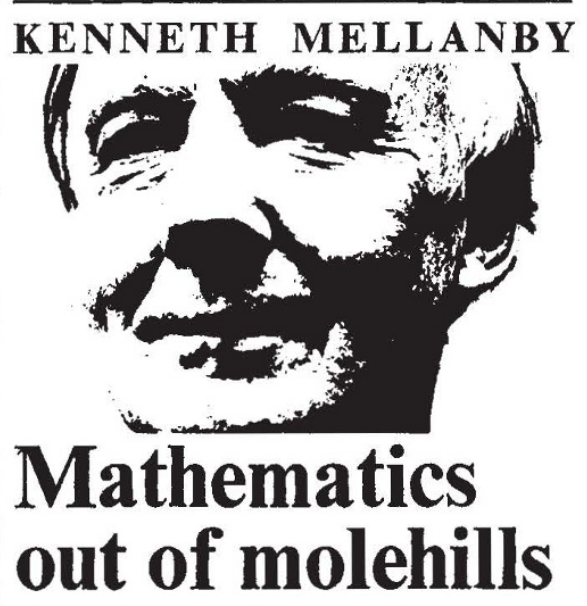

THERE is generally an optimum period for any worker to continue in a particular field of research. It takes a little time to become familiar with a new topic, productivity may then build up, but eventually he becomes stale and the "law of diminishing returns" seems to ensure that progress becomes slower and slower. This is the time to change direction, though after a fallow period the field may once again become productive.

These musings were prompted by a reader who writes: "Last week I was staying on a farm and looked at mole tracks as the moles went about ruining a newly seeded lawn. Why do the tracks so often run at right angles; they seem to turn through $90^{\circ}$ at various points along their track. Perhaps they are particularly geometric beasts". Now I have been interested in moles for years and have even produced a monograph on the subject, but familiarity has evidently prevented me from recognising the interest of the tunnel pattern. My immediate reaction on receiving the letter was to go out and see what wild moles were actually up to. I looked with new interest at the working in my own garden, four acres of near-wilderness where wildlife is encouraged. I also returned to my main study area, Monks Wood National Nature Reserve. I may perhaps remind readers that moles, like most of our native fauna, are primarily woodland creatures, though they have been able to adapt to man-made habitats like farmland and lawns. I found everywhere, and clearly recorded in my own data made in previous years in farmland. that they do indeed have a prediliction for right angled bends in their tunnels, particularly in new excavations in cultivated soil. In the wood, where they live in permanent tunnels which house generation after generation of solitary moles, this pattern is not so noticeable, possibly because of modificattions over the years where repairs have been executed

Another observation revealed something which may also be a function of 
I write to you from a Soviet camp for literature of non-political content, inpolitical prisoners, located in the cluding specialised literature and literaLesnoy Settlement in Mordovia (Camp ture published in countries on friendly ZhKh-385/19). The problem to which terms with the USSR. Subject to so I would like to draw your attention is many restrictions and in practice totally of vital interest not only to me person- isolated from any source of informaally, but also to a large number of tion, a scientist soon feels he lags Soviet political prisoners-scientists behind contemporary science and that who are in camps for expressing their he is losing his professional skills. In political views openly.

In this letter I will not concern myself with whether and up to what extent reached in approximately three years. the persecution of citizens for exercising their right to free speech, guaranteed to them by law, is lawful and justified, though this fact in itself should also come to the attention of world scientific opinion. However, this question is too vast for a thorough examination in a letter. Furthermore, it is up to each individual scientist to decide whether he wishes to express himself on this subject or not.

I would only like to draw your attention to the conditions in which these political prisoners are held and how this affects their professional skills. Among us there are physicists, mathematicians, biologists, civil engineers, philologists, philosophers and many others. Personally, I am an astronomer, specialised in the field of meteoric astronomy and astro-biology. Each one of us, regardless of his political views, remains, above all, a scientist and aims to preserve his professional skills under any circumstances.

However, this is impossible under the conditions which prevail in the camp. A specialist who is sent to a camp is deprived of the opportunity to follow developments in his field effectively. In accordance with Soviet law, to receive literature, periodically or in any other way, published abroad is categorically forbidden. This ban extends to

\section{Letter from the Soviet Union}

We are serving sentences of five, seven years and longer. We face total creative impotence. We are not just deprived of freedom for a given period of time. We are deprived of our chosen work and our profession forever.

These restrictions are imposed not only on publications from abroad. Literature published in the USSR can be received only through specialised shops, which deal by post. According to the rules operating the book market in the USSR, in practical terms this means that one can acquire literature which has been published only recently and even then only if it is in smal demand and cannot be sold over the counter. Any monograph or reference book indispensable to work which has been published a few years back is impossible to acquire. To receive literature from private individuals (even from relatives) is strictly forbidden. Fear of the written word reaches such proportions that even cuttings from the Soviet press are not allowed in the mail. To receive scientific infor- mation in private letters from colleagues-such a fashionable method during the Renaissance and widely used at present-is also impossible for us. Probably as a result of inadequate education of those who guard us during our imprisonment, letters of such 'strange' content arouse special suspicion. Their censoring takes many long months and quite often they are not even delivered. Letters from abroad excite particular apprehension.

The disqualification of scientific workers is speeded along by purely physiological reasons. We are all forced tis do heavy physical work, and many of us who are no longer so young are badly equipped for it. This leaves us no time or energy for intellectual pursuits. The food is highly insufficient, low in calories and in quality (lacking in protein, carbohydrates, phosphorus, vitamins). A condition of semistarvation is normal for us. I will not dwell on this problem further as it has already been examined repeatedly. I will only add that all this contributes in bringing about a sharp decrease of intellectual potential, and a weakening of memory, and so on.

For the sake of humanity and professional solidarity, I beg you, and through you scientists throughout the world, to intercede on our behalf in this difficult situation. I appeal to you to focus your attention on the plight of your colleagues. There is no need for political action. We only ask you to secure for Soviet scientists the right of unhindered use of scientific literature, and the right to maintain scientific contacts. Please send your colleagues in prison camps books and journals and other scientific material, and in this way ease the conditions in which they are held. $-K . A$. Lyubarskii this same geometrical behaviour. Monks Wood consists of blocks of woodland, divided by grassy rides of short turf. The moles spend most of their time in an anastomosing network of permanent burrows under the trees, but this system is joined at frequent intervals by mole runs which cross under the rides. These almost always run straight across the ride; they never run along it. And the burrow comes out of one woodland block and enters the other, at almost exactly ninety degrees.

How and why this happens is difficult to understand. Why does the mole never make a right-angle under the woodland ride, which may be several yards across? Under a lawn, which the ride resembles, a zig-zag would normally occur in this distance. A mole busily burrowing underground in the wood must, somehow, recognise that it has reached the edge of the ride, and it must receive some stimulus which causes it to burrow in a particular direction towards some goal on the other side.

My correspondent raised another, more familiar, problem. He asked: "How can one decently remove moles when they are wrecking your lawn without actually putting them to death?". This is difficult, and I usually try to persuade people to learn to live with their moles. Especially in a clay soil a mole (there is usually only one at a time in the average garden) makes a series of hills from the spoil as it digs its tunnel system, but when this is complete there is little further evidence of its presence. The mole is territorial, and will keep other individuals away.

There are various repellants on the market. If they work, they usually divert the animals to a neighbour's garden. Generally they are unsuccessful, or they only close up a section of the burrow system. The Caper Spurge, as attractive plant in its own right, is reputed to keep the garden free, but it seldom does.

If people must be rid of moles, they have to kill them. The commercial scissor trap will catch one troublesome beast, and worms baited with strychnine will wipe out a large population. But the garden, particularly if adjacent to a wood, will always be liable to reinvasion. The same will happen if the neighbours find an effective repellant! It is best to rely on the territorial in stincts of your own moles, hoping that thev will do little more damage and will keep out all other members of their own species. 